
2 Research Square
Preprints are preliminary reports that have not undergone peer review.
They should not be considered conclusive, used to inform clinical practice,
or referenced by the media as validated information.

\title{
Barriers to vasectomy acceptance and uptake in Nigeria: a review of the literature
}

Mary Ndu ( $\sim$ mayntondu@hotmail.com)

University of Western Ontario https://orcid.org/0000-0002-5221-3898

Lauren J. Wallace

Dodowa Health Research Centre, Research and Development Division, Ghana Health Service

Elysee Nouvet

University of Western Ontario

Gertrude Odezugo

USAID Nigeria

Amina Aminu

Pathfinder International Nigeria

Systematic Review

Keywords: Family planning, Vasectomy, Barriers, Gender, Nigeria, Attitude

Posted Date: August 5th, 2021

DOI: https://doi.org/10.21203/rs.3.rs-737344/v1

License: (c) (7) This work is licensed under a Creative Commons Attribution 4.0 International License. Read Full License 


\section{Abstract}

There is growing support of male involvement in reproductive health and the integration of voluntary vasectomy services into national family planning programs in lower resource contexts; yet, the prevalence of women of reproductive age who rely on vasectomy in African countries such as Nigeria, is less than 1 percent. We conducted this review to gain a broader understanding of current sociocultural and health systems' conditions that need to be addressed to expand the integration and acceptability of vasectomy as an option for family planning in Nigeria. To explore this, we scoped existing literature on vasectomy in Nigeria between 2009 to 2021. Findings reveal that there is a strong awareness of vasectomy among men in Nigeria. Yet, several factors prevent men from having the same confidence in vasectomy as they have in female biomedical methods. Three significant themes emerged: 1) fear; 2) religious and cultural beliefs, which overlapped with fear; and 3 ) access to health providers and health facilities. These findings have implications for future family planning policies, strategies and programmes in the country.

\section{Introduction}

As of 2015 , the global acceptance rate for vasectomy was 2.5 per cent. Today, that acceptance rate has dropped to 2 per cent ${ }^{1,2}$. Although not as popular as female tubal ligation, vasectomy is more effective (providing twice the protection when used in comparison to female methods) less painful with less recovery time, and less costly ${ }^{3-7}$. There is growing support of male involvement in reproductive health and the integration of voluntary vasectomy services into national family planning programs in lower resource contexts; yet, the prevalence of women of reproductive age who rely on vasectomy in African countries such as Nigeria, is less than 1 percent ${ }^{8,9}$. Higher rates of vasectomy continue to be found in contexts such as North America (12\%) ${ }^{1}$. In Canada, for instance, $22 \%$ of women rely on vasectomy, and it is the most widely used method ${ }^{10}$.

Two bedrock principles of reproductive health programs are the availability of a wide range of methods, such that couples seeking contraception are able to make a voluntary and informed choice, and the importance of gender-sensitive and gender-equitable approaches ${ }^{2}$. Although there is growing global support of and traction on male involvement in family planning programmes, from the perspective of vasectomy, there are considerable disconnects between programme realities and stated commitments in policies and global declarations ${ }^{5}$.

In African contexts, there tends to be more dependence on short-term methods such as condoms, pills, injectables, for limiting future births, compared to long term or permanent methods. These short-term methods are more expensive (in the long term) and also less effective due to product failure, discontinuation, and or incorrect use. In Nigeria, where the total fertility rate is 5.4 children per woman, the most common methods used by married women are injectables and implants, while the most popular method among unmarried women is the male condom ${ }^{11}$. Although $17 \%$ of married women currently use a method of family planning, $0 \%$ rely on vasectomy as a method ${ }^{1,11}$. Improving acceptance of and access to vasectomy requires creating an enabling environment in which sociocultural, policy, and health systems issues that influence health programs and social norms related to family planning (FP) and vasectomy are considered ${ }^{12}$. Ultimately, the goal of this review is to broaden understandings of current sociocultural and health systems conditions that need to be addressed to expand the integration and acceptability of vasectomy as an option for family planning in Nigeria.

\section{Method}

\section{Source identification and retrieval strategy}

The search goal was to retrieve as many publications as possible (both journal articles and grey literature) related to vasectomy as a family planning strategy in Nigeria. The primary author conducted an electronic database search of peer-reviewed publications in Medline OVID published in English between 2009 to 2021.

Inclusion criteria were that an article or report be in English and focus on one of the following: men's views on reproductive control options and male contraceptives (if the study reported on vasectomy), health professionals' knowledge and attitudes about vasectomy, and also studies that focus explicitly on women, if they also examine women's attitudes about vasectomy. Studies focusing solely on reproductive methods for use by women, hormonal or animal studies, training manuals, and commentaries or editorials were excluded from review. The search strategy string is outlined in Annex A. Following the Medline OVID search, the same search terms and restriction on years of publication were used to conduct a search using google scholar.

To identify relevant grey literature, the primary author hand searched the websites of key organizations that support family planning in Nigeria. The primary author, who worked as a programme manager for a major organization involved in family planning efforts in Nigeria, drew on their knowledge of the Nigerian public health landscape to identify these organizations. A list of all organizations whose websites were searched for grey literature $(n=5$; United Nations, Ministry of Health, FHI360, Planned Parenthood, Marie Stopes Nigeria) is provided in Table 2.

Sources reviewed were selected from a combined 993 studies retrieved from Medline OVID, Google scholar, and hand searching of websites. After removal of duplicates $(n=28)$, results (960 sources) were reviewed first by the title and then abstract to further remove articles that fell within the exclusion criteria. A read of the entire source was then conducted by the first author to determine further suitability for inclusion. In the end, 12 peer reviewed articles and 4 guidelines/strategies were retained for full analysis. Figure 1 is the Preferred Reporting Items for Systematic Reviews and Meta-Analyses (PRISMA) diagram detailing the search and retrieval process.

This review is limited to studies that were published and available on the searched databases. The search was limited to English language sources. The identification of grey literature through a hand search of organization websites involved with family planning in Nigeria limited the search to publicly available reports which were posted online. 


\section{Analysis}

Sources meeting the inclusion criteria were uploaded to MAXQDA. Open coding was used to generate broad themes based on the objectives of the study. To generate relevant sub-themes, the coding process involved coding and recoding informed by an inductive and iterative approach ${ }^{13,14}$. Three broad themes were identified: 1) fear; 2) religious and cultural beliefs, which overlapped with fear; and 3) access to health providers and health facilities. Specific fears identified under the broad theme of fear included fear of erectile dysfunction, surgical complications, loss of libido, and cultural and religious beliefs, which overlapped with fear. Specific supply-side issues identified as sub-themes included counselling for vasectomy, accessing family planning clinics, publicity, and health worker capacity to provide vasectomy.

\section{Results}

Sources retrieved included results on qualitative interviews, surveys, and four national strategies/reports. Studies were based on data collected in various parts of Nigeria, including the south-south ${ }^{15-19}$, southeast ${ }^{20}$, northcentral ${ }^{21}$, and southwest regions ${ }^{22-25}$. The studies were all cross-sectional studies with sample sizes ranging between 100-300. Participants reported a range of educational levels, with many including participants with education ranging from a university education to no formal education. Studies included participants from a mix of religious affiliations, with the majority of participants identifying as Christians, Muslims, or traditionalists, the three major religions in Nigeria. The studies in their totality also show a fair number of participants across the three major ethnic groups in Nigeria: Igbo, Yoruba, and Hausa. A majority of the studies focused on men as primary source of data, but three studies focused on women's perspectives on vasectomy ${ }^{16,19,25}$. Studies recruited participants who were either in union, single or widowed. Table 1 provides further detail on each of the studies retained for analysis.

Men and women remain apprehensive about vasectomy. Most studies indicate there is high awareness of vasectomy among men in Nigeria regardless of their social location with an average of 60 percent of participants claiming to have heard or read about vasectomy. One study found a high level of awareness about FP methods in general among the various study groups in Benue (middlebelt region) and Oyo (southwestern region), though long-acting methods such as vasectomy were less frequently mentioned than short-term contraceptives ${ }^{26}$. While the level of awareness about vasectomy did not differ drastically across demographic and regional contexts, data suggests that men and women in urban areas with more education had more knowledge about vasectomy surgery being available in Nigeria.

Studies indicate a high awareness of vasectomy amongst women; however, women's preferences for reproductive control options varied across these studies, making it difficult to identify a clear pattern. One study conducted in the northcentral region of Nigeria found that among 400 women, of which 89.75 percent approved the use of family planning by their husbands, 81.5 percent disapproved of vasectomy as the method of choice ${ }^{21}$. However, another study, based on a cross sectional study among 200 respondents (100 men and 100 women) in the southwestern part of Nigeria, found that only 14.8 percent of women were firmly against vasectomy and would not elect to have their husbands or male relative have the procedure. Although men and women have high awareness of vasectomy, a very low percentage-about 26 percent of those surveyed - stated they were willing to take up vasectomy in the future. Several factors prevented men and women from having the same confidence in vasectomy as a method of family planning as they have in female biomedical methods. Three broad themes were identified as key barriers to the use of vasectomy. These are: 1) fear; 2) religious and cultural beliefs, which overlapped with fear; and 3) access to health providers and health facilities. The roles played by each of these barriers in limiting the use of vasectomy in Nigeria are described below.

Table 1

Characteristics of the study

\begin{tabular}{|llll|}
\hline Country & Authors' name & Study Design & Population \\
\hline Nigeria & Ogunlaja et al., 2017 & Cross sectional survey & Male between the ages of 25-35 years \\
\hline Nigeria & Ebeigbe et al., 2011 & Cross sectional survey & Resident doctors (Male and female) aged 30-49 \\
\hline Nigeria & Ezegwui et al., 2009 & Cross sectional study & Male aged 15-50 \\
\hline Nigeria & Akpamu et al., 2010 & Cross sectional study & Male aged 25-60 years of age \\
\hline Nigeria & Owopetu et al., 2015 & Descriptive survey research design & Male aged 20-80years old \\
\hline Nigeria & Onasoga et al., 2013 & Descriptive research design & Male aged 15-54years old \\
\hline Nigeria & Otovwe et al., 2018 & Cross sectional study & Male aged 10-69years \\
\hline Nigeria & Tijani et al., 2013 & Cross sectional study & Male and female aged 20-50 years \\
\hline Nigeria & Tamunomie et al., 2016 & Cross sectional study & Female who attended antenatal clinics aged 15-50 years old. \\
\hline Nigeria & Desmennu et al., 2016 & Cross sectional study & Male aged 25-65 \\
\hline Nigeria & Utoo and Utoo, 2010 & Cross sectional study & Female aged 19-45 years and above \\
\hline Nigeria & Babalola et al., 2017 & Longitudinal data analysis & Women of reproductive age \\
\hline
\end{tabular}

\section{Barriers to the use of vasectomy}


Fear of the negative effects of vasectomy was the most prominent theme observed in all the studies reviewed. This fear manifested in various ways: fear of losing libido ${ }^{19,20}$, and fear of losing fertility, especially if there is a need to remarry or have another child ${ }^{17,18,22,24}$ were common. There was also the fear of surgery and surgical complications ${ }^{16,19,23}$.

Five of the studies found that men believed a vasectomy is a form of castration 17,18,20,22,24. The prevalence of this fear varied by study. One study found that 45 percent of men viewed vasectomy as a form of castration and would not recommend it to anyone ${ }^{17}$. In contrast, two studies found a lower percentage; 4.4 percent and 15.3 percent of men respectively viewed vasectomy as a form of castration ${ }^{22,24}$. Two studies found that women also shared these same fears that once a man gets sterilized, they are castrated and lose any desire for sex ${ }^{19,20}$.

In three studies, concerns of erectile dysfunction resulting from vasectomy were expressed commonly by women and men ${ }^{19-21}$. Men and women in these studies worried that vasectomy resulting in loss of libido would consequently provoke promiscuity among wives since male partners would no longer able to satisfy them sexually. Three studies found that men feared surgery, surgical complications, and the non-reversible nature of vasectomy ${ }^{19,20,22}$.

\section{Religious and cultural beliefs}

In some studies, specific religious or cultural beliefs were associated with respondents' opposition to vasectomy. In five studies, respondents were opposed to vasectomy because it is an affront to God and his commandment to procreate $16,18,22,24,27$. Two studies found that over 50 percent of respondents strongly agreed that religion and culture were critical hindrances to vasectomy uptake in Nigeria ${ }^{18,20}$. Both studies included a mix of muslims, christians, and traditionalists indicating a shared belief regardless of religious affiliation. Some studies described specific cultural beliefs that led men to object to vasectomy. For instance, there is a common traditional belief in many parts of the southeastern and southsouthern states of Nigeria that one will be reincarnated with the bodily defaults present at their death. As such, men worry that if they adopt vasectomy, this decision will affect the state of their body at reincarnation ${ }^{16}$. In the eastern region of Nigeria, there are additional cultural prohibitions against body modification. Some traditional titles and events, such as Ozo title, for example, forbid any procedures that remove or adjust any part of a man who wishes to be member or who is an existing member ${ }^{28,29}$.

It should be noted that not all studies found religious beliefs to be a barrier to vasectomy. Two studies found that the effect of religion on men and women's perspective on vasectomy was not statistically significant 19,25 .

\section{Access to health providers and health facilities}

Access to providers who will counsel for and can provide vasectomy services represents another important barrier to uptake of vasectomy in Nigeria. Four studies found that health providers who did counsel for other family planning methods did not counsel for vasectomy, which could explain the low uptake of vasectomy $16,17,20,22$. Three studies also reported that men rely on health providers to decide on an appropriate family planning method $17,20,22$. Men in these studies said they would accept vasectomy if they were properly informed and had their fears surrounding vasectomy dispelled by health providers.

A survey of gynecologists illuminates the context of counselling (or lack thereof) for vasectomy in Nigeria ${ }^{16}$. Among 104 resident gynaecologists in Edo and Delta states of the south-south region, only 5.8 percent admitted to counselling for a vasectomy with 47.1 percent reporting that they rarely counsel or never consider counselling. Gendered cultural norms and a lack of confidence and skill informed physicians' lack of counselling for vasectomy. Most gynecologists (89.4\%) admitted to only counselling for tubal ligation with 64.4 percent citing tubal ligation as a much better option for family planning than vasectomy. Physicians justified their approach by referencing gendered cultural norms, with 84.6 percent of respondents stating that the average Nigerian man will not accept vasectomy. Another 15.4 percent of respondents in this study said they did not have the requisite skill to perform a vasectomy.

In two studies, men (ranging from 7 to $66.2 \%$ respectively) suggested that lack of access to family planning clinics in general is a barrier to their acceptance and use of vasectomy (Desmennu et al., 2016; Onasoga et al., 2013). A review of four key national policies, including National Task shifting Policies, the National FP Blueprint and the National Communication Plan on family planning, and the most recent 2018 Nigeria Demographic and Health Survey (DHS), reveals that there is a culture of silence on vasectomy in Nigeria. These documents are devoid of any mention of vasectomy or male sterilization as a family planning method. Vasectomy is considered a specialist service in Nigeria, requiring referral from a lower health facility to a higher facility (Shattuck et. al. 2016). Despite the fact that the DHS (2019) contained questions on vasectomy uptake, the authors do not actually report on vasectomy data. National family planning policies also do not provide guidelines for vasectomy counselling or service provision and there is no reference to the need or opportunity for health workers to scale up their capacity to provide vasectomy. Training manuals on family planning including several at the secondary and tertiary levels, remain focused on improving services for female methods. 
Table 2

List of grey literature reviewed

\begin{tabular}{|c|c|}
\hline FHI & https://www.fhi360.org/resource/promoting-evidence-based-vasectomy-programming \\
\hline $\begin{array}{l}\text { Planned } \\
\text { Parenthood }\end{array}$ & https://www.plannedparenthood.org/learn/birth-control/vasectomy \\
\hline Maries Stopes & https://www.mariestopes.org.au/contraception/vasectomy/ \\
\hline $\begin{array}{l}\text { UN-DESA: } \\
\text { Global } \\
\text { Contraceptive } \\
\text { Trend } 2015\end{array}$ & https://www.un.org/development/desa/pd/sites/www.un.org.development.desa.pd/files/files/documents/2020/Jan/un_2019_contracep \\
\hline $\begin{array}{l}\text { UN-DESA: } \\
\text { Global } \\
\text { Contraceptive } \\
\text { Trend } 2019\end{array}$ & https://www.un.org/development/desa/pd/sites/www.un.org.development.desa.pd/files/undesa_pd_report_2015_trends_contraceptive_u \\
\hline $\begin{array}{l}\text { The National } \\
\text { Family } \\
\text { Planning } \\
\text { Communication } \\
\text { Plan guide all } \\
\text { family planning } \\
\text { related health } \\
\text { promotion } \\
\text { activity in the } \\
\text { country. }\end{array}$ & https://www.health.gov.ng/doc/national\%20family\%20planning\%20communication\%20plan\%202017\%20(revised).pdf \\
\hline $\begin{array}{l}\text { Nigeria task } \\
\text { shifting/task } \\
\text { policy devolves } \\
\text { skilled birth } \\
\text { attendance to } \\
\text { lower level } \\
\text { healthworkers } \\
\text { to address the } \\
\text { shortage of } \\
\text { healthworkers } \\
\text { at the PHCs. }\end{array}$ & https://www.health.gov.ng/doc/TSTS.pdf \\
\hline $\begin{array}{l}\text { The National } \\
\text { Family } \\
\text { Planning } \\
\text { Blueprint } 2014 \\
\text { is the national } \\
\text { guide for all } \\
\text { family planning } \\
\text { service-related } \\
\text { activities. }\end{array}$ & https://health.gov.ng/doc/Nigeria\%20FP\%20B_print.pdf \\
\hline $\begin{array}{l}\text { The Nigeria } \\
2020 \text { National } \\
\text { Family } \\
\text { Planning } \\
\text { Blueprint } \\
\text { updates the } \\
\text { previous plan. } \\
\text { This is the } \\
\text { latest version } \\
\text { and does not } \\
\text { mention } \\
\text { vasectomy. }\end{array}$ & https://health.gov.ng/doc/Final-2020-Blueprint.pdf \\
\hline
\end{tabular}

\section{Discussion And Recommendations}

The purpose of this review is to broaden understanding of current sociocultural and health systems conditions in Nigeria that need to be addressed in order to expand the integration and acceptability of vasectomy as an option for family planning in Nigeria. There are many studies focused on understanding the family planning landscape in Nigeria ${ }^{30-39}$. However, despite the fact that vasectomy is more effective and less costly than tubal ligation, and the importance of gender-equitable approaches, studies have often focused on understanding how to increase women's and men's acceptance of female methods. To the best of our knowledge, this is the first such review of the use and acceptance of vasectomy in Nigeria.

We found that although men and women have high awareness of vasectomy, a very low percentage-about 26 percent of those surveyed - stated they were willing to take up vasectomy in the future. Several factors prevented men and women from having the same confidence in vasectomy as a method of family planning as they have in female biomedical methods: 1) fear; 2) religious and cultural beliefs, which overlapped with fear; and 3) access to health providers and health facilities. Fear manifests in misconceptions about loss of libido and strength with the view that vasectomy is a form of castration. Some fears are driven by specific religious and socio-cultural practices and ideas. However, it is evident that the low uptake of vasectomy is not a consequence of only inadequate knowledge about vasectomy amongst the general population. Access to health facilities and providers appears to also contribute to the low uptake of vasectomy. At family planning clinics, counselling on methods of contraception is routine, yet both users and providers report that vasectomy is often not included in this counselling. Gendered cultural norms and a lack of confidence and skill informed physicians' lack of counselling for vasectomy. Our 
review of policies and strategies also suggests that limited discussion of vasectomy in clinical family planning settings is at least in part sustained by a lack of interest in, or prioritization of, vasectomy in national policy fora.

Many other studies on vasectomy in West Africa reviewed report that fear, and religious and cultural beliefs, which are also framed as a lack of knowledge, contribute to the poor uptake of vasectomy in the region. ${ }^{40-43}$. These studies recommend increased publicity and public awareness campaigns on vasectomy. Yet, the crucial role that health care providers play in mediating access to vasectomy merits highlighting. Although many providers do not provide counselling on vasectomy to men because they do not feel they have the skills to perform this operation, ${ }^{16}$ support for healthcare providers in Nigeria to develop these skills is not evident in the literature reviewed. Some studies reported that a significant percentage of men surveyed would opt for vasectomy if healthcare providers could dispel their fears and the procedure was available ${ }^{16,25}$. Providers' capacity for and attitudes towards vasectomy were also identified as a key barrier in a ten-year review of vasectomy programming in resource poor settings ${ }^{12}$. Shattuck and colleagues found that a lot of interventions focused on introducing vasectomy in resource-poor areas but failed to build the capacity of providers and address their personal biases. In places where vasectomy has successfully been scaled up, such as Iran, United States, and Rwanda, interventions both addressed demand and supply side issues, creating continual demand for services, as well as ensuring access to well-trained healthcare providers. In Nigeria, and other West African settings, vasectomy is a specialized surgery which can only be performed by a urologist and requiring referral from a lower-level facility to a higher-level facility. In other settings, such as Rwanda and United States of America, vasectomy services have been extended from hospitals to health centers ${ }^{44-47}$. Providers have also been trained to perform no scapel vasectomies (NSV), which is a less invasive method requiring only local anesthesia. Shifting vasectomy services to lower levels, and training providers in NSV could contribute to creating more demand for vasectomy services in Nigeria.

Other studies have also noted a lack of policy support for vasectomy in national family planning policies and strategies ${ }^{48-51}$. The lack of active endorsement of vasectomy reinforces the idea that family planning is women's responsibility ${ }^{9,52-54}$, and reflects the broader issue that men's health needs are often not an institutionalised component of reproductive health agendas and programming 9,48,55-57. While the support of men is crucial in women's reproductive health, it is also important to ensure policies, strategies and programmes are inclusive of men's reproductive health needs. To achieve this, governments and health agencies should aim to initiate well-designed health policies, strategies, and programmes that seek to promote gender equitable positive reproductive health among men.

\section{Declarations}

Competing interests: The authors declare no competing interests.

\section{References}

1. United Nations. Department of Economic and Social Affairs. Population Division. Contraceptive use by method 2019: data booklet. Trends Contracept Use Worldw 20192019;: 25

2. United Nations. Department of Economic and Social Affairs. Population Division. Trends in Contraceptive Use Worldwide 2015.2016 DOI:10.18356/f52491f9-en.

3. Trussell J, Lalla AM, Doan Q V., Reyes E, Pinto L, Gricar J. Cost effectiveness of contraceptives in the United States. Contraception 2009. DOI:10.1016/j.contraception.2008.08.003.

4. White K, Campbell A, Hopkins K, Grossman D, Potter JE. Barriers to Offering Vasectomy at Publicly Funded Family Planning Organizations in Texas. Am J Mens Health 2017; 11: 757-66.

5. Jacobstein R. The kindest cut: Global need to increase vasectomy availability. Lancet Glob Heal 2015; 3: e733-4.

6. Shih G, Turok DK, Parker WJ. Vasectomy: The other (better) form of sterilization. Contraception. 2011. D0I:10.1016/j.contraception.2010.08.019.

7. Tsuruta JK, Dayton PA, Gallippi CM, et al. Therapeutic ultrasound as a potential male contraceptive: Power, frequency and temperature required to deplete rat testes of meiotic cells and epididymides of sperm determined using a commercially available system. Reprod Biol Endocrinol $2012 ; 10: 7$.

8. United Nations. World Population Prospects 2019: Data Booklet. Dep Econ Soc Aff Popul Div 2019;: 1-25.

9. Hardee K, Croce-Galis M, Gay J. Population Council Knowledge Commons Men as contraceptive users: Programs, outcomes and recommendations. 2016 https://knowledgecommons.popcouncil.org/ (accessed Oct 7, 2020).

10. Eisenberg ML, Lipshultz LI. Estimating the Number of Vasectomies Performed Annually in the United States: Data From the National Survey of Family Growth. J Urol 2010; 184: 2068-72.

11. NPC. Nigeria Demographic Health Survey 2018. 2019 https://dhsprogram.com/publications/publication-fr359-dhs-final-reports.cfm.

12. Shattuck D, Perry B, Packer C, Quee DC. A review of 10 years of vasectomy programming and research in low-resource settings. Glob. Heal. Sci. Pract. 2016; 4: 647-60.

13. Srivastava P, Hopwood N. A Practical Iterative Framework for Qualitative Data Analysis. Int J Qual Methods 2009; 8: 76-84.

14. Barnett-Page E, Thomas J. Methods for the synthesis of qualitative research: a critical review. BMC Med Res Methodol 2009 ; 9: 59.

15. Akpamu U, Nwoke EO, Osifo UC, Igbinovia ENS, Adisa AW. Knowledge and acceptance of 'vasectomy as a method of contraception' amongst literate married men in Ekpoma, Nigeria. African J Biomed Res 2010; 13: 153-6.

16. Ebeigbe PN, Igberase GO, Eigbefoh J. Vasectomy: A survey of attitudes, counselling patterns and acceptance among Nlgerian residents Gynaecologists. GHANA Med J 2011; 45: 101-4. 
17. Otovwe A, R A O-BO, Okandeji-Barry O. RA. Knowledge and perception of vasectomy among male staffs of Novena University Ogume Delta State Nigeria. IOSR J Nurs Heal Sci 2018; 7: 2320-1940.

18. Onasoga OA, Edoni EER, Ekanem J, Ekiokenigha ER. Knowledge and attitude of men towards vasectomy as a family planning method in Edo State, Nigeria. J Res Nurs Midwifery (JRNM 2013; 2: 13-21.

19. Tamunomie N, Vademene O, Journal OW-SM, $2016 \mathrm{U}$. Knowledge and attitude toward vasectomy among antenatal clinic attendees in a tertiary health facility in Nigeria. Sahel Med J Online 2016; 19: 201-5.

20. Ezegwui HU, Enwereji JO. Attitude of men in Nigeria to vasectomy. Int Health 2009; 1: 169-72.

21. Utoo B, Utoo P. Awareness and attitude of women towards their spouse's use of vasectomy as a fertility control method in Jos, North-Central Nigeria. Jos J Med 2010; 5. DOI:10.4314/jjm.v5i1.62019.

22. Ogunlaja OA, Ogunlaja SE, Aworinde OO, Ogunlaja IP, Bojuwoye MO. A survey on the knowledge, attitude and acceptance of male sterilzation among men in Ogbomoso, South West Nigeria. Res J Heal Sci 2018; 5: 204.

23. Desmennu AT, Arulogun OS, Ajuwon AJ, Adeyimika TD, Oyedunni SA, Ademola JA. Antecedent factors relating to the adoption of vasectomy among married men in peri-urban communities of Ibadan, Nigeria. Int $J$ Nurs Midwifery 2016; 8: 47-54.

24. Owopetu C, Chukwuma S, Nwozichi C. Knowledge and attitude of men about vasectomy as a method of family planning among married men wornig in Babcock University Ogun State Nigeria. Int J Nurs Midwifery 2014; 7: 30-5.

25. Tijani KH, Ojewola RW, Yahya GL, Oluwole AA, Odusanya B. Attitudes and acceptance of Nigerians towards vasectomy- A comparison of married men and women in lagos. East Afr Med J 2013; 90: 89-94.

26. Babaloba S, John N. Factors underlying the use of long-acting and permanent family planning methods in Nigeria: A qualitative study. New York, 2012 http://www.respond-project.org/pages/files/6_pubs/research-reports/Study5-Use-Dynamics-Study-Nigeria-August2012-FINAL.pdf.

27. Desmennu AT, Titiloye MA, Owoaje ET. Behavioural risk factors for sexually transmitted infections and health seeking behaviour of street youths in Ibadan, Nigeria. Afr Health Sci 2018; 18: 180-7.

28. Madukasi FC. Ozo Title: An Indigenous Institution In Traditional Religion That Upholds Patriarchy In Igbo Land South-Eastern Nigeria. Int J Soc Sci Humanit Invent 2018; 5: 4640-52.

29. Nweke IO. Ozo title institution in Igbo land in relation to politics in Nigeria: A comparative analysis. OGIRISI a New J African Stud 2019; 15 : 96-108.

30. Babalola S, Oyenubi O, Speizer IS, Cobb L, Akiode A, Odeku M. Factors affecting the achievement of fertility intentions in urban Nigeria: Analysis of longitudinal data. BMC Public Health 2017; 17: 1-8.

31. Solanke BL. Factors influencing contraceptive use and non-use among women of advanced reproductive age in Nigeria. J Heal Popul Nutr 2017; 36: 114.

32. Solanke BL, Oyinlola FF, Oyeleye OJ, llesanmi BB. Maternal and community factors associated with unmet contraceptive need among childbearing women in Northern Nigeria. Contracept Reprod Med 2019; 4: 1-12.

33. Solanke BL, Banjo 00, Oyinloye BO, Asa SS. Maternal grand multiparity and intention to use modern contraceptives in Nigeria. BMC Public Health 2018; 18: $1-15$.

34. Okigbo CC, Speizer IS, Corroon M, Gueye A. Exposure to family planning messages and modern contraceptive use among men in urban Kenya, Nigeria, and Senegal: A cross-sectional study. Reprod Health 2015; 12: 1-11.

35. Bishwajit G, Tang S, Yaya S, et al. Factors associated with male involvement in reproductive care in Bangladesh. BMC Public Health 2017; 17: 1-8.

36. Adelekan A, Omoregie P, Edoni E. Male Involvement in Family Planning: Challenges and Way Forward. Int J Popul Res 2014 ; $2014:$ 1-9.

37. Adeleye OA, Aldoory L, Parakoyi DB. Using local culture and gender roles to improve male involvement in maternal health in southern Nigeria. $J$ Health Commun 2011; 16: 1122-35.

38. Sinai I, Nyenwa J, Oguntunde O. Programmatic implications of unmet need for contraception among men and young married women in northern Nigeria. Open Access J Contracept 2018; Volume 9: 81-90.

39. Olugbenga-Bello Al, Adeyemi A, Adeoye O, Salawu M, Aderinoye A, Agbaje M. Contraceptive prevalence and determinants among women of reproductive age group in Ogbomoso, Oyo State, Nigeria. Open Access J Contracept 2016;: 33.

40. Sihlabela -Shongwe PV. The perceptions and acceptability of vasectomy as a family planning option by adult Swazi men in Swaziland. 2019 https://repository.smu.ac.za/handle/20.500.12308/616 (accessed Oct 7, 2020).

41. Arwen Bunce, Greg Guest, Hannah Searing, et al. Factors Affecting Vasectomy Acceptability in Tanzania. Int Fam Plan Perspect 2007; 33: $13-21$.

42. Nesro J, Sendo EG, Yesuf NT, Sintayehu Y. Intention to use vasectomy and associated factors among married men in Addis Ababa, Ethiopia. BMC Public Health 2020; 20: 1-8.

43. Ntakirutimana C, Umuziga P, Nikuze B, White R, Meharry P, Adejumo O. Vasectomy is family planning: factors affecting uptake among men in eastern province of Rwanda. Rwanda J Med Heal Sci 2019; 2: 126.

44. Haws JM, McKenzie M, Mehta M, Pollack AE. Increasing the Availability of Vasectomy In Public-Sector Clinics. Fam Plann Perspect 1997; 29: 185.

45. Davis J, Hurley L, Stratton S. Successful No-scalpel Vasectomy Pilot Program in Rwanda. 2010 https://www.intrahealth.org/sites/ihweb/files/files/media/rwandas-commitment-to-making-family-planning-services-available-toall/Tech_Brief_No_Scalpel_Vasectomy_web.pdf.

46. Labrecque M, Kagabo L, Shattuck D, et al. Strengthening vasectomy services in Rwanda: introduction of thermal cautery with fascial interposition. Contraception 2013; 87: 375-9. 
47. Barone MA, Hutchinson PL, Johnson CH, Hsia J, Wheeler J. Vasectomy in the United States, 2002. J Uro/ 2006; 176: 232-6.

48. Labrecque M, Pile J, Sokal D, et al. Vasectomy surgical techniques in South and South East Asia. BMC Urol 2005; 5: 10.

49. The ACQUIRE Project. 'Get a Permanent Smile'- Increasing Awareness of, Access to, and Utilization of Vasectomy Services in Ghana. Acquir. Knowl. 2006. https://toolkits.knowledgesuccess.org/sites/default/files/get a permanent smile.pdf.

50. Tynan A, Vallely A, Kelly A, et al. Health workers, health facilities and penile cutting in papua new guinea: implications for male circumcision as an HIV prevention strategy. PN G Med J 2011; 54: 109-22.

51. Tynan A, Vallely A, Kelly A, et al. Vasectomy as a proxy: extrapolating health system lessons to male circumcision as an HIV prevention strategy in Papua New Guinea. BMC Health Serv Res 2012; 12: 299.

52. Nian C, Xiaozhang L, Xiaofang P, Qing Y, Minxiang L. Factors Influencing the Declining Trend of Vasectomy in Sichuan, China. Southeast Asian J Trop Med Public Heal 2010; 41. https://www.tm.mahidol.ac.th/seameo/2010-41-4/28-4783.pdf.

53. Hardee K, Croce-Galis M, Gay J. Are men well served by family planning programs? Reprod. Health. 2017; 14: 1-12.

54. Kohan S, Simbar M, Taleghani F. Women's experience regarding the role of health centers in empowering them for family planning. Iran J Nurs Midwifery Res 2012; 17: S150-6.

55. Tosa W. Understanding male involvement in vasectomy (case study scenario in Madang Province, PNG). 2019 https://www.vasectomy.org.au/faqs/vasectomy-vs-tubal-ligation/ (accessed Oct 7, 2020).

56. White K, Campbell A, Hopkins K, Grossman D, Potter JE. Barriers to Offering Vasectomy at Publicly Funded Family Planning Organizations in Texas. Am J Mens Health 2017; 11: 757-66.

57. Sharma S, KC B, Khatri A. Factors influencing male participation in reproductive health: a qualitative study. J Multidiscip Healthc 2018; Volume 11: 601-8.

\section{Annex A: Medline Ovid}

Ovid MEDLINE(R) ALL <1946 to July 09, 2021>

1 exp *Nigeria/ or nigeri*.mp.

2 family planning.mp. or exp Family Planning Services/

3 (child spacing or child limiting).mp. [mp=title, abstract, original title, name of substance word, subject heading word, floating sub-heading word, keyword heading word, organism supplementary concept word, protocol supplementary concept word, rare disease supplementary concept word, unique identifier, synonyms]

42 or 3

5 exp Vas Deferens/ or exp Vasectomy/ or vasectom*.mp.

6 exp Sterilization/ or sterilization.mp.

7 Sterilization, Involuntary/ or sterilization.mp.

85 or 6 or 7

$9 \quad 4$ and 8

$10 \quad 1$ and 9

\section{Figures}




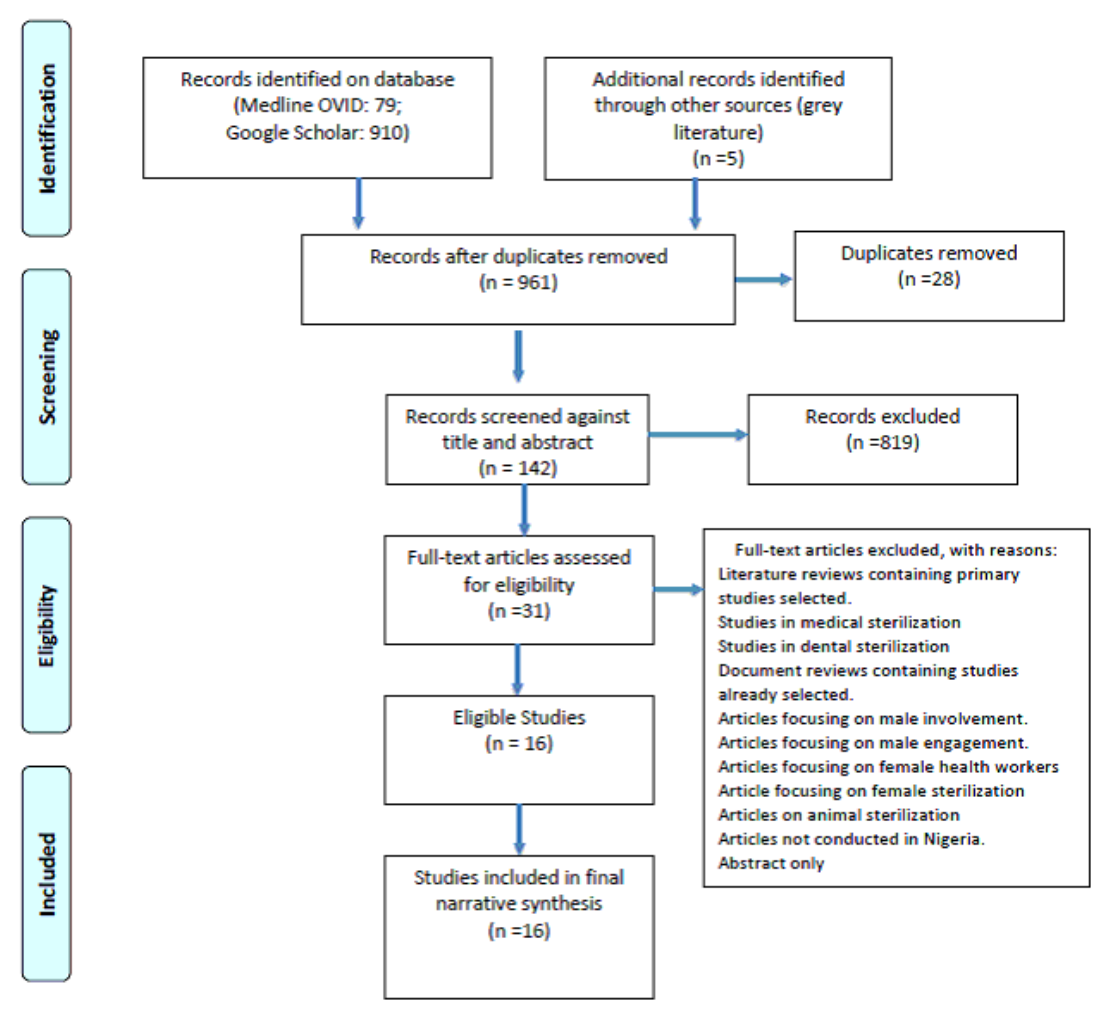

Figure 1: PRISMA Flow Diagram

Figure 1

PRISMA Flow Diagram 